\title{
Allelopathic activity of Stratiotes aloides on phytoplankton-towards identification of allelopathic substances
}

\author{
Gabi Mulderij · Birgit Mau · Ellen van Donk · \\ Elisabeth M. Gross
}

(C) Springer Science+Business Media B.V. 2007

\begin{abstract}
The allelopathic activity of the aquatic macrophyte, Stratiotes aloides, was determined with laboratory experiments. Active compounds exuded in the medium or present in plant tissue were extracted using standard procedures and solid phase extraction (SPE). The activity towards
\end{abstract}

Guest editors: R. D. Gulati, E. Lammens, N. De Pauw \& E. Van Donk

Shallow lakes in a changing world

G. Mulderij $(\bowtie) \cdot$ E. van Donk

Department of Food Web Studies, NIOO-KNAW,

Centre for Limnology, Nieuwersluis 3631 AC,

The Netherlands

e-mail: g.mulderij@nioo.knaw.nl

E. van Donk

e-mail: e.vandonk@nioo.knaw.nl

G. Mulderij · E. van Donk

Department of Ecology, Aquatic Ecology and Environmental Biology Section, University of Nijmegen, PO Box 9010, Nijmegen 6500 GL,

The Netherlands

B. Mau · E. M. Gross

Limnological Institute, University of Konstanz, PO Box M659, Konstanz 78457, Germany

B. Mau

e-mail: Mau.Birgit@web.de

E. M. Gross

e-mail: Elisabeth.Gross@uni-konstanz.de various cyanobacteria and chlorophytes was tested in two different bioassay systems using agar plates and liquid cultures of phytoplankton. Extracts and exudates of $S$. aloides affected phytoplankton growth. SPE-enriched exudates and enriched water from a natural Stratiotes stand caused inhibition of target species, however, also some controls were active. Phytoplankton species exhibited differential sensitivity to extracts of $S$. aloides. We observed inhibitory and stimulatory effects on phytoplankton. In general, more cyanobacteria than other phytoplankton species were inhibited, and the inhibition of cyanobacteria was stronger. In most cases, nutrient ( $\mathrm{P}$ or $\mathrm{K}$ ) limitation of Synechococcus elongatus and Scenedesmus obliquus decreased the sensitivity of these species towards allelochemicals from Stratiotes aloides, except for P-limited cultures of Scenedesmus. The allelopathically active compound(s) from Stratiotes are moderately lipophilic and most likely no phenolic compounds. Our results indicate that allelopathy (besides nutrient interference and shading) might also account for the low phytoplankton and filamentous algae densities in the vicinity of Stratiotes plants, at least during certain phases of the life-cycle of Stratiotes.

Keywords Allelopathy - Aquatic macrophyte · Exudate · Growth inhibition - Nutrient limitation 


\section{Introduction}

Aquatic macrophytes play a crucial role in stabilizing the clear water state in shallow mesotrophic and eutrophic lakes (Scheffer, 1998; Burks et al., in press). They can stimulate changes to clear water situations by a range of mechanisms (see review Van Donk \& Van de Bund, 2002). One of those mechanisms is the excretion of inhibitory substances that reduce phytoplankton growth (= allelopathy, e.g., Gross, 2003). The release of these compounds may be an effective trait of submerged macrophytes to gain competitive advances against other photoautotrophs.

Only a few allelochemicals from submerged aquatic macrophytes are structurally elucidated (Wium-Andersen et al., 1982; Gross et al., 1996). Previous experiments (Mulderij et al., 2005a, b) provided evidence for allelopathic interference of Stratiotes aloides with phytoplankton species, but the nature of the active compound(s) was not investigated. $S$. aloides is a dioecious, perennial aquatic macrophyte, native to Europe and Siberia (Cook \& Urmi-König, 1983). A part of its life cycle is submerged (Bloemendaal \& Roelofs, 1988) and the plants overwinter as turions or entire (but rootless) plants on the bottom of the lake. The macrophyte becomes buoyant in spring as a result of increased photosynthesis and remains floating on the water surface until autumn (De Geus-Kruyt \& Segal, 1973). Especially during its submerged phase, Stratiotes might be favoured by the ability to produce allelopathic compounds that inhibit phytoplankton growth.

Other mechanisms for the exclusion of phytoplankton in the proximity of water soldier have been proposed. The availability of potassium or sodium might be limiting phytoplankton growth in S. aloides stands and further, co-precipitation of phosphates with calcium might be an important mechanism (Brammer, 1979; Brammer \& Wetzel, 1984). Other authors, however, indicated allelopathic activity of Stratiotes. Extracts of the macrophyte showed inhibitory effects even at the lowest concentration tested ( $2 \mathrm{~g} \mathrm{FM} / \mathrm{l}$, Jasser, 1995). Usenko et al. (2002) showed that phenolic acids might be responsible for algicidal effects of Stratiotes. Both studies, however, did not prove that Stratiotes really excreted allelopathic compounds, an important issue to asses the ecological importance of allelopathic interactions. Recent laboratory experiments showed that exudates of Stratiotes inhibited the green alga Scenedesmus obliquus and induced colony formation in this alga (Mulderij et al., 2005a). Further, allelopathic effects of Stratiotes exudates on the cyanobacterium Microcystis aeruginosa and the eustigmatophyte Nannochloropsis limnetica were observed (Mulderij et al., 2005b).

We performed bioassay-directed extractions and fractionations to elucidate the chemical characteristics of allelopathic substances in extracts and exudates of Stratiotes, and were especially interested whether the active compounds are hydro- or lipophilic. We also tested if the sensitivity of target organisms to Stratiotes would increase when they were cultured under nutrient limiting conditions, as Reigosa et al. (1999) stated that target organisms under stress (e.g., nutrient limitation) become more susceptible to additional stressors (e.g., allelopathy) than equivalent target organisms not further stressed.

\section{Materials and methods}

\section{Macrophyte culture}

The Stratiotes plants originated from a ditch in Tienhoven $\left(52^{\circ} 10^{\prime} 0^{\prime \prime} \mathrm{N}, 5^{\circ} 4^{\prime} 60^{\prime \prime} \mathrm{E}\right)$, the Netherlands, and were collected in July 2003. The plants were carefully rinsed with tap water and transferred into 5001 aquaria filled with $10 \mathrm{~cm}$ sediment originating from the same ditch and with copper-free tap water. The macrophytes were grown at a density comparable to moderate densities in the field (ca. $10 \mathrm{~g} \mathrm{FM/l),} \mathrm{and} \mathrm{water}$ was renewed fortnightly. The aquaria were illuminated $\left(30 \mu \mathrm{mol} \mathrm{m}{ }^{-2} \mathrm{~s}^{-1}\right) 16 \mathrm{~h}$ per day and the water temperature was $18 \pm 1^{\circ} \mathrm{C}$. At the start of an experiment, plants were transferred to sediment-free aquaria with macrophyte medium (Mulderij et al., 2005a). 
Target organisms

We used axenic monocultures of twelve phytoplankton species, consisting of cyanobacteria, green algae and an eustigmatophyte. Anabaena sp. PCC 7120 and A. variabilis P9 ATCC 29413 were used in agar diffusion assays ( $A D A s$, see Bioassays), while the four Microcystis aeruginosa strains (NIVA-CYA 140 (toxic), NIVA-CYA 43, V131 (from E. Kardinaal), and PCC 7820, the latter two non-toxic), the cyanobacterium Synechococcus elongatus (SAG 89.79), the green algae Chlorella minutissima (CCAP 211/52), Chlamydomonas reinhardtii (NIVA-CHL 13), Scenedesmus obliquus (CCAP 276/3A), Selenastrum capricornutum (NIVA-CHL 1) and the eustigmatophyte Nannochloropsis limnetica (Krienitz 1998/3) were used in liquid culture assays (LCAs, see Bioassays). All cyanobacteria were cultured in cyanobacteria medium (Jüttner et al., 1983; with modifications as in Gross et al., 1991), while all green algae and Nannochloropsis were cultured in modified WC medium (Guillard \& Lorentzen, 1972; modified by Lurling, 1999).

Phosphate- (P) or potassium- (K) limited cultures of $S$. obliquus and $S$. elongatus were established by centrifuging ( 6 min., 2,300 rpm) aliquots of non-limited cultures twice. After each centrifugation step the supernatant was removed and cells were resuspended in $\mathrm{P}$ - or K-limited medium. $\mathrm{P}$-limited medium was created by substituting $50 \mu \mathrm{M} \mathrm{K}_{2} \mathrm{PO}_{4}$ by $1 \mu \mathrm{M} \mathrm{K}_{2} \mathrm{PO}_{4}$ and $40 \mu \mathrm{M} \mathrm{KCl}$. Klimited medium was created by substituting $50 \mu \mathrm{M}$ $\mathrm{K}_{2} \mathrm{HPO}_{4}$ with $1 \mu \mathrm{M} \mathrm{K}_{2} \mathrm{HPO}_{4}$ and $40 \mu \mathrm{M} \mathrm{Na}{ }_{2} \mathrm{H}$ $\mathrm{PO}_{4}$ (Alahari \& Apte, 2004). P- or K-limited batch cultures $(300 \mathrm{ml})$ were grown for at least 9 days on an orbital shaker $(110 \mathrm{rpm})$ at $22^{\circ} \mathrm{C}, 50 \mu \mathrm{mol}$ PAR $\mathrm{m}^{-2} \mathrm{~s}^{-1}$ with a photoperiod of 16:8 (L:D).

\section{Extraction}

Stratiotes plants were carefully rinsed with tap water, shock-frozen with liquid nitrogen, and immediately lyophilized for $24 \mathrm{~h}$. This material was homogenized and stored in the dark at room temperature until further use. Later, this plant material was extracted $(1 \mathrm{ml}$ solvent per $10 \mathrm{mg}$ plant dry mass) for $2 \mathrm{~h}$ at room temperature under continuous stirring. As solvents we used water, methanol and acetone in different mixtures $(50 \%$ or $70 \%[\mathrm{v} / \mathrm{v}]$ in water, and $100 \%)$. Extracts were filtered (Whatman $\mathrm{GF} / \mathrm{F}$ ) to remove plant particles, evaporated under vacuum to dryness and resuspended in $50 \%[\mathrm{v} / \mathrm{v}]$ aqueous methanol at a final concentration equivalent to $100 \mathrm{mg}$ extracted dry mass (DM) per ml. Extracts were stored at $-20^{\circ} \mathrm{C}$. Solvent controls were performed using the same procedure without adding plant material.

Fractionation of crude extracts

Crude extracts were fractionated using solid phase extraction (SPE). An aliquot of crude extract (20 mg extracted DM) dissolved in $2 \mathrm{ml}$ $50 \%[\mathrm{v} / \mathrm{v}]$ aqueous methanol, was diluted 1:25 with water and passed over a preconditioned SPE-C18 cartridge (Varian Bond Elute, 3cc, $2 \mathrm{~g}$ sorbens) and the eluate was collected. Then the cartridge was stepwise eluted with each two reservoir volumes $(10 \mathrm{ml})$ of $40,60,70,80,90$ and $100 \%[\mathrm{v} / \mathrm{v}]$ methanol (in water). Those seven fractions were collected separately, evaporated to dryness and redissolved in $50 \%[\mathrm{v} / \mathrm{v}]$ aqueous methanol for further use in bioassays.

Heat stability and polyvinylpolypyrrolidone (PVPP) test

Crude extracts of Stratiotes were heated for $5 \mathrm{~min}$ at $95^{\circ} \mathrm{C}$. Immediately thereafter the extracts were cooled down in ice, evaporated to dryness, and resuspended in $50 \%[\mathrm{v} / \mathrm{v}]$ aqueous methanol. To test for the presence of phenolic compounds, we conducted a polyvinylpolypyrrolidone (PVPP, Sigma P6755) test modified after Loomis \& Battaile (1966). A suspension of PVPP in water (2 g PVPP/20 ml water) was added to an aliquot of the crude extract (v/v 1:1) and stored overnight at $4^{\circ} \mathrm{C}$. Thereafter, the suspension was centrifuged ( $5 \mathrm{~min} ., 4,000 \mathrm{~g}$ ) and the supernatant used in the bioassays.

\section{Exudation}

Possible allelopathic compounds, exuded into the water by Stratiotes, were investigated with three 
approaches. Laboratory approaches (set-ups $1 \&$ 2): Incubating single or multiple plants in microcosms. Field approach (set-up 3): Collecting water from a natural Stratiotes stand in Lake Naardermeer (nature reserve). In set-up 1 (single plant culture), we filled $1.5-1$ glass vials $(\varnothing 10 \mathrm{~cm}$, $20 \mathrm{~cm}$ height) with 11 macrophyte medium (Mulderij et al., 2005a) and one Stratiotes plant (25-30 g FM) from the laboratory culture. Control vials only received medium. All vials were kept at $16^{\circ} \mathrm{C}$ and approx. $60 \mu \mathrm{mol}$ PAR m ${ }^{-2} \mathrm{~s}^{-1}$ (L:D 14:10). After 1, 2 and 5 days, the culture water of three vials (one control and two with Stratiotes) was used for analyses. In set-up 2 (microcosms), two 50 l-aquaria were filled with 301 macrophyte medium. One aquarium served as control and was filled with medium, while the other aquarium was filled with medium and eight Stratiotes plants (ca. $200 \mathrm{~g} \mathrm{FM}$ ) originating from Giethoorn $\left(52^{\circ} 45^{\prime} 0^{\prime \prime} \mathrm{N} 6^{\circ} 5^{\prime} 0^{\prime \prime} \mathrm{E}\right.$, The Netherlands), collected the week before the start of the experiment. After 1, 2 and 3 days, 11 water of each aquarium was collected for further analysis. For set-up 3, water samples (1 1) were collected in the vicinity of Stratiotes plants. As a control, two sites without Stratiotes were sampled: one in the same ditch (Ditch 1) just outside the Stratiotes stand and the other in an other ditch (Ditch 2) in the nature reserve. In ditch 2, Stratiotes plants were absent during the whole experiment. Samples were collected between 7 April and 14 June 2004.

All samples (set-ups 1, 2 \& 3) were filtered over Whatman GF/F and then over $0.2 \mu \mathrm{m}$ celluloseacetate membrane filters (Schleicher \& Schuell). Potentially exuded allelopathic compounds were trapped on preconditioned C18filters $\left(\varnothing 47 \mathrm{~mm}, 3 \mathrm{M}\right.$ Empore ${ }^{\mathrm{TM}}$, Phenomenex) and eluted with $100 \%$ methanol (set-up 1) or with 50, 90, and 100\% methanol (set-ups 2 \& 3). All fractions were evaporated to dryness and resuspended in $50 \%$ [v/v] aqueous methanol.

\section{Bioassays}

We conducted two types of bioassays under sterile conditions: Agar diffusion assays, ( $A D A s$, Flores \& Wolk, 1986; Gross et al., 1991) and liquid culture assays, ( $L C A s$, Schrader et al., 1997; slightly modified by Erhard \& Gross, submitted).

Agar diffusion assay $(A D A)$ : Extracts or SPE fractions ( 0.5 to $3 \mathrm{mg}$ extracted plant DM) were spotted in multiple intervals onto $1 \%$ agar plates so that the diameter never exceeded $5 \mathrm{~mm}$. Subsequently, a second layer containing cyanobacteria medium, target cells and heated $4 \%$ agar (final agar strength: 1\%) was added. Target organisms were inoculated at an optical density (OD) of $40 \mathrm{mAU}$ at $530 \mathrm{~nm}$. The agar plates were

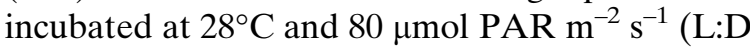
16:8) for one week. Exudates were spotted in concentrations equivalent to 40,120 , and $240 \mathrm{ml}$ culture water (set-up 1, equal to 1.2, 3.6 and 7.2 g FM) or $600 \mathrm{ml}$ (set-up $2 \& 3$, equal to $3.96 \mathrm{~g} \mathrm{FM}$ for set-up 2). Extracts, exudates and SPE fractions with algicidal activity caused clearing areas in the algal lawn. All ADAs were carried out at least in duplicate.

Liquid culture assay ( $L C A)$ : Each of the four rows on a 24-well plate was assigned six different concentrations of A) extract + target cells, B) extract, C) solvent control + target cells, or D) solvent control. Extracts were pipetted into the wells and the solvent was evaporated. Then, per well, $2 \mathrm{ml}$ culture with target cells $\left(\mathrm{OD}_{530 \mathrm{~nm}}\right.$ : $40 \mathrm{mAU}$ ) in the respective medium were added. Plates were incubated for one week at either $21^{\circ} \mathrm{C}$ and $60 \mathrm{PAR} \mathrm{m}^{-2} \mathrm{~s}^{-1} \mathrm{~L}: \mathrm{D}$ 16:8 (NIOO) or at $28^{\circ} \mathrm{C}$ and 60 PAR m $\mathrm{m}^{-2} \mathrm{~s}^{-1}$ under continuous illumination (University of Konstanz), depending on the phytoplankton species. All LCAs were conducted in triplicate and the growth of target cells, as percentage relative to the control, was calculated for each extract concentration as follows:

$$
\begin{aligned}
& \text { Growth [as \% of control] } \\
& =\frac{\text { Row } A-\text { Row } B}{\text { Row } C-\text { Row } D} \times 100 \%
\end{aligned}
$$

The first LCA was conducted with four different concentrations of Stratiotes extract $(0,0.75,1.5$ and $3.75 \mathrm{mg} \mathrm{DM} / \mathrm{ml} ; L C A 1)$ and all target species. In the second LCA ( LCA 2) lower extract concentrations $(0,0.5,1.0$ and 
$1.5 \mathrm{mg} \mathrm{DM} / \mathrm{ml}$ ) and only some target species were used. In this way we determined which extract concentration and which test organisms should be used in the following assays. The two most sensitive species of cyanobacteria and green algae were chosen as target organisms for the next LCAs.

We conducted two short term LCAs with $3 \mathrm{mg}$ $\mathrm{DM} / \mathrm{ml}$ Stratiotes extract, to test when allelopathic effects of Stratiotes extract become apparent and how long they persist without extra addition of fresh extract. The first short term LCA with $S$. elongatus and $S$. obliquus was sampled after 0,2 , $4,6,8,24$, and $48 \mathrm{~h}$ incubation (LCA 3). The second short term LCA with only $S$. elongatus was sampled after 24, 48, 72 and $216 \mathrm{~h}$ incubation (LCA 4).

The next LCA ( $L C A 5)$ was conducted with extract concentrations ranging from 0 to $5.5 \mathrm{mg}$ $\mathrm{DM} / \mathrm{ml}$ at increments of $0.5 \mathrm{mg} \mathrm{DM} / \mathrm{ml}$ ). This enabled the determination of threshold levels of inhibition/stimulation of the growth of $S$. elongatus and $S$. obliquus in the presence of Stratiotes extract. LCAs 3-5 were conducted with nutrient ( $\mathrm{K}$ or $\mathrm{P}$ ) limited and non-limited target cells.

Two additional LCAs were conducted with SPE fractions of the crude extract ( $L C A S P E$ ) and PVPP treated extracts ( $L C A P V P P)$ added in four concentrations $(0,1,3$ and $5 \mathrm{mg} \mathrm{DM} /$ $\mathrm{ml})$.

\section{Statistical analysis}

The influence of Stratiotes extracts on the growth of target cells in LCAs $\left(\mathrm{OD}_{530 \mathrm{~nm}}\right.$ values) was assessed by means of one-way ANOVA $(\alpha=0.05$, Fowler et al., 1998). Prior to the ANOVA, all data were tested for normality (Kolmogorov-Smirnov test, $\alpha=0.05$ ) and homoscedasticity (Levene's test, $\alpha=0.05$ ). All data followed a normal distribution, but sometimes heteroscedasticity was observed. Therefore, logtransformations were carried out. If these transformations did not remove heteroscedasticity, an $\alpha$-value of 0.01 was used (Fowler-Walker \& Connell, 2002). When the ANOVA revealed significant effects, a Tukey multiple comparisons test $(\alpha=0.05)$ was applied to group homogeneous means.

\section{Results}

Allelopathic activity of Stratiotes extracts

ADAs with Anabaena sp. and A. variabilis showed that Anabaena sp. was not strongly inhibited by any of the extracts. $A$. variabilis was much more sensitive and strongly inhibited by 50 and $70 \%$ methanol or acetone extracts. Increasing extract concentrations caused increased clearing zones. The strongest inhibition of $A$. variabilis was observed when Stratiotes was extracted with 50\% [v/v] aqueous acetone. This solvent was subsequently used for further extractions.

M. aeruginosa V131 was the most sensitive cyanobacterium, exhibiting a significant $(P<0.001)$ growth inhibition in $L C A 1$ of $32 \%$ already at $1 \mathrm{mg} \mathrm{DM} / \mathrm{ml}$ (Fig. 1a). S. elongatus was inhibited $(56 \%)$ by extract concentrations above $1.5 \mathrm{mg} \mathrm{DM} / \mathrm{ml}$ (Fig. 1b). Other cyanobacteria showed no significant response ( $L C A 1$ ) or even a significant growth stimulation ( $L C A 2$ ), depending on the experiment (Table 1). While all tested green algae and the eustigmatophyte $N$. limnetica exhibited no significant inhibition or stimulation in $L C A 1$, we observed an inhibition above $1 \mathrm{mg}$ $\mathrm{DM} / \mathrm{ml}$ (Fig. 1c) with $N$. limnetica and a stimulation of all chlorophytes at 0.5 or $1 \mathrm{mg} \mathrm{DM} / \mathrm{ml}$ in LCA 2 (Table 1).

Short term LCA 3 showed a significant $(P<0.001)$ growth stimulation of $S$. elongatus $(130 \%)$ and $S$. obliquus $(282 \%)$ after $48 \mathrm{~h}$ incubation in Stratiotes extract, while short term $L C A$ 4 exhibited a significant $(P=0.002)$ inhibition on $S$. elongatus only after 216 h $(45 \pm 2 \%)$.

Fractionation of crude extracts

The ADA with A. variabilis and SPE fractions of crude extract showed strong inhibitory effects of the 80 and $90 \%$ methanol SPE fractions (Table 2). An additional LCA with crude extract 
Fig. 1 Growth relative to the control of Microcystis aeruginosa (a),

Synechococcus elongatus (b), and Nannochloropsis limnetica (c) at different concentrations of Stratiotes extract in the first two liquid assays. Bars indicate average values $(n=3)$, error bars are $1 \mathrm{SE}$. + and - indicate significant inhibitory and stimulatory effects on the growth of the phytoplankton species
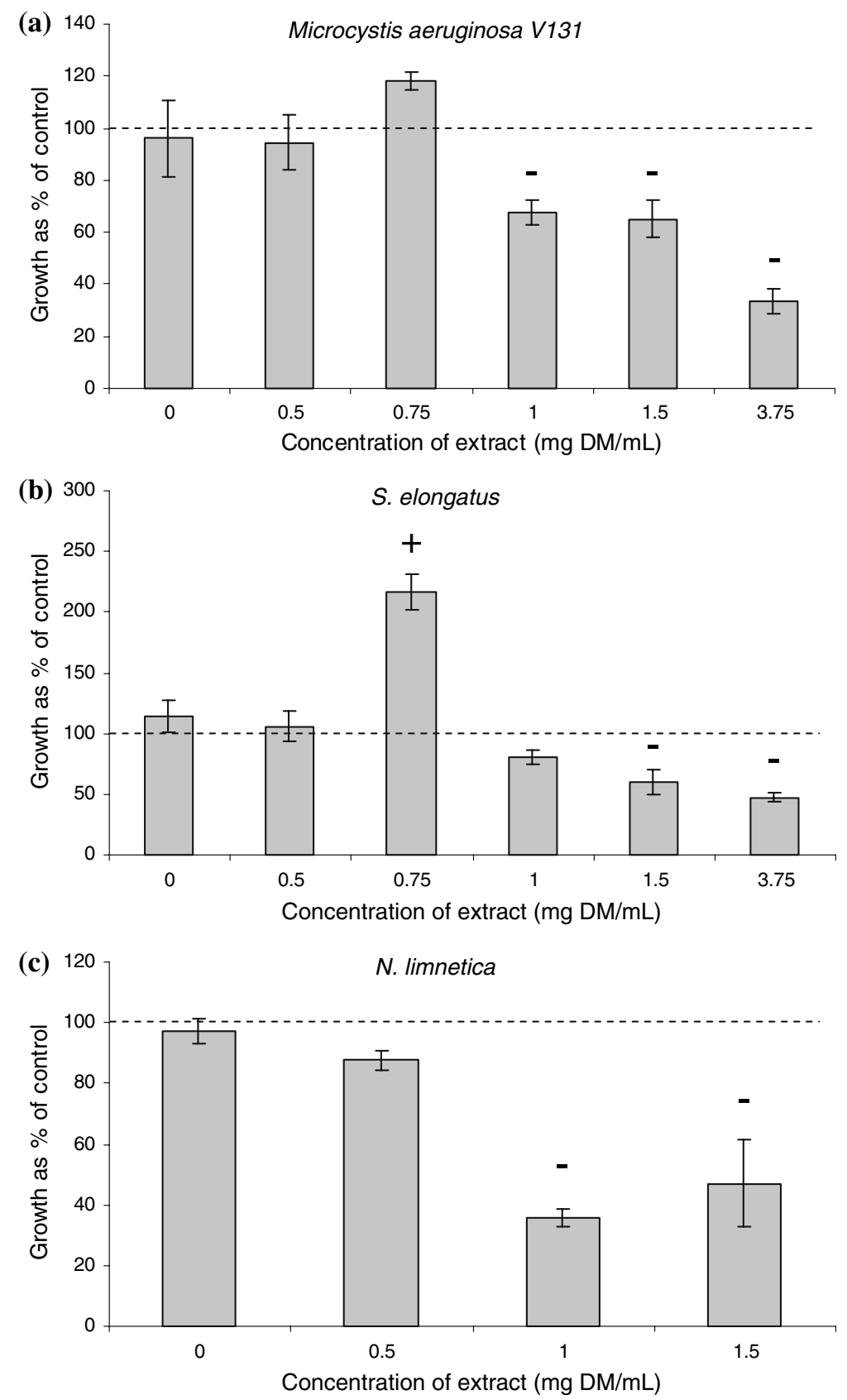

and its SPE fractions ( $L C A S P E$ ) showed significant $(P<0.001)$ effects on the growth of S. elongatus (Fig. 2b). Crude extract and the 90 and $100 \%$ methanol SPE fractions showed significant inhibitory effects at concentrations of 3 and $5 \mathrm{mg} \mathrm{DM} / \mathrm{ml}$, and the $100 \%$ fraction also already at $1 \mathrm{mg} \mathrm{DM} / \mathrm{ml}$, between 36 and 94\% (Fig. 2b). The $50 \%$ SPE fraction, on the contrary, showed significant stimulatory effects at concentrations of 1 and $3 \mathrm{mg} \mathrm{DM} / \mathrm{ml}$ (Fig. 2b).

Heat stability and polyvinylpolypyrrolidone (PVPP) test

ADAs showed that Stratiotes extract remains allelopathically active after heating. The clearing 
Table 1 Results statistical analyses of liquid culture assays 1 and 2 ( $L C A 1 \& L C A 2$ ). Effects of extract addition were either stimulatory $(+)$, inhibitory $(-)$ or not clear $(0)$ with threshold values indicated in parenthesis

\begin{tabular}{|c|c|c|c|c|}
\hline & \multicolumn{2}{|l|}{ LCA 1} & \multicolumn{2}{|l|}{ LCA 2} \\
\hline & \multicolumn{2}{|c|}{ 0-3.75 mg DM/ml } & \multicolumn{2}{|c|}{$0-1.5 \mathrm{mg} \mathrm{DM} / \mathrm{ml}$} \\
\hline & $P$-value & Effect & $P$-value & Effect \\
\hline \multicolumn{5}{|l|}{ Green algae } \\
\hline C. minutissima & 0.603 & 0 & $<0.001$ & $+(0.5)$ \\
\hline C. reinhardthii & 0.402 & 0 & $<0.001$ & $+(0.5)$ \\
\hline S. obliquus & 0.057 & 0 & $<0.001$ & $+(0.5)$ \\
\hline S. capricornutum & 0.635 & 0 & $<0.001$ & $+(1.0)$ \\
\hline \multicolumn{5}{|l|}{ Eustigmatophyte } \\
\hline N. limnetica & 0.222 & - & $<0.001$ & $-(1.0)$ \\
\hline \multicolumn{5}{|l|}{ Cyanobacteria } \\
\hline M. aeruginosa CYA 43 & $0.044 *$ & - & $<0.001$ & $+(0.5)$ \\
\hline M. aeruginosa CYA 140 & 0.317 & 0 & $<0.001$ & $+(0.5)$ \\
\hline M. aeruginosa V131 & 0.056 & - & $<0.001$ & $-(1.0)$ \\
\hline M. aeruginosa PCC 7820 & 0.230 & - & $<0.001$ & $+(0.5)$ \\
\hline S. elongatus & 0.033 & $-(1.5)$ & 0.100 & $-(1.5)$ \\
\hline
\end{tabular}

The one-way ANOVA of the growth as percentage of control, was carried out on a series of 24 values per phytoplankton species (3 replicates, 2 treatments: control and Stratiotes, and four extract concentrations: $0,0.5,1.0 \mathrm{and} 1.5 \mathrm{mg} \mathrm{DM} / \mathrm{ml}$ or 0 , $0.75,1.5$ and $3.75 \mathrm{mg} \mathrm{DM} / \mathrm{ml})$

* Criterion for significance was 0.01 , see Statistical analysis

zone of untreated or heat-treated extracts did not differ. Further, three independent ADAs showed that PVPP treatment of Stratiotes crude extract did not or only slightly remove inhibitory effects. PVPP treatment neither removed the inhibitory activity of the extract in an LCA ( $L C A P V P P$ ) with $S$. elongatus (Fig. 2a versus b).

Phosphorus and potassium limitation of S. elongatus and S. obliquus

LCA 5 with $S$. elongatus showed significant $(P<0.001) \quad$ stimulatory effects of P-limited cultures above extract concentrations of $2.5 \mathrm{mg}$ $\mathrm{DM} / \mathrm{ml}$ (Fig. 3a), while non-limited cultures were significantly $(P<0.001)$ inhibited $(45 \%)$ by concentrations above $4.0 \mathrm{mg} \mathrm{DM} / \mathrm{ml}$ (Fig. 3a). P-limited and non-limited $S$. obliquus cultures, were significantly $(P<0.001)$ stimulated (up to $1600 \%)$ by Stratiotes extract at concentrations above $0.5 \mathrm{mg} \mathrm{DM} / \mathrm{ml}$ (Fig. 3b), with the pronounced effects for non-limited cultures (Fig. 3b).

The short term LCA 4 showed significant stimulatory effects of Stratiotes extract on P-limited cultures of $S$. elongatus and S. obliquus. The stimulatory effects on P-limited cultures were stronger (130 vs. $414 \%$ for S. elongatus; 282 vs. $844 \%$ for $S$. obliquus) and occurred earlier (after 24 instead of $48 \mathrm{~h}$ ) than on non-limited cultures.

K-limited cultures of $S$. elongatus were less strongly inhibited than non-limited ones. Whereas the non-limited $S$. elongatus cultures were significantly $(P<0.001)$ inhibited by crude extract and the 90 and $100 \%$ SPE fraction (Fig. 2b), no significant inhibitory effects were observed with K-limited cultures (Fig. 2c). The

Table 2 Algicidal activity of SPE-fractions of Stratiotes extract ( $50 \%$ acetone) on $A$. variabilis

\begin{tabular}{lll}
\hline Fraction & \multicolumn{2}{l}{ Clearing area diameter $(\mathrm{cm})$} \\
\cline { 2 - 3 } & $2 \mathrm{mg} \mathrm{DM}$ & $3 \mathrm{mg} \mathrm{DM}$ \\
\hline Flow through & - & - \\
$40 \%$ Methanol & - & - \\
$60 \%$ Methanol & $(+)$ & $(+)$ \\
$70 \%$ Methanol & - & - \\
$80 \%$ Methanol & $(0.7)$ & $(0.8)$ \\
$90 \%$ Methanol & 0.8 & 1.1 \\
$100 \%$ Methanol & $(+)$ & $(+)$
\end{tabular}

Aliquots were applied in two concentrations in the agar diffusion assay

( ) inhibition less strong. Algal cells not completely absent in the clearing areas, only lower densities observed 
Fig. 2 Growth relative to the control in non-limited (a, b) and K-limited cultures (c) of Synechococcus elongatus when exposed to different concentrations $(0,1,3$ and $5 \mathrm{mg} \mathrm{DM} / \mathrm{ml})$ of Stratiotes extract (crude extract) or SPE fractions (50-, 90-, and $100 \%$ Methanol) either treated (a) or not treated $(\mathbf{b}, \mathbf{c})$ with polyvinylpolypyrrolidone (PVPP). Bars indicate average values $(n=3)$, error bars are $1 \mathrm{SE}$. + and - indicate significant inhibitory and stimulatory effects on the growth of the phytoplankton species
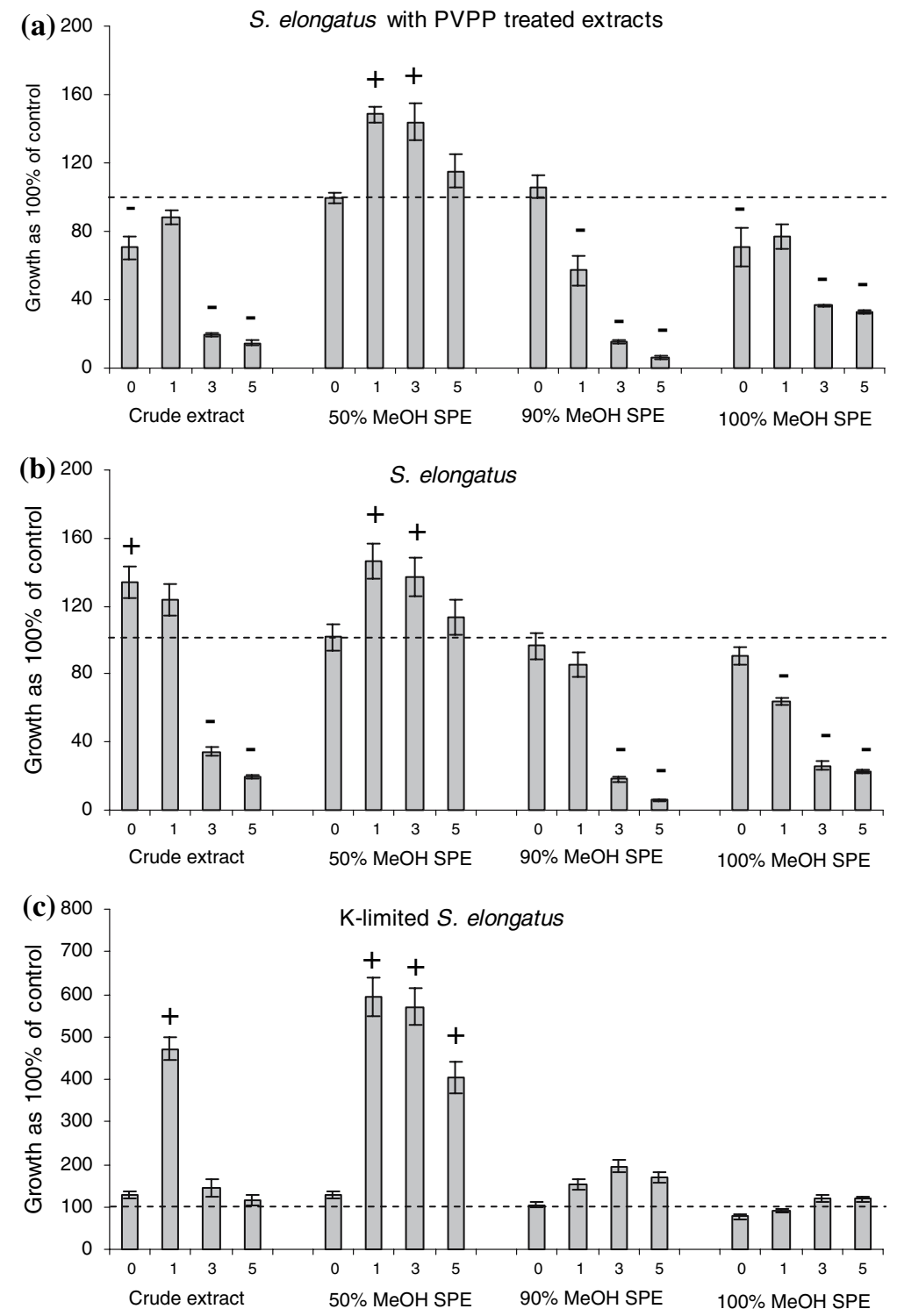

$50 \%$ SPE fraction exhibited a significant growth stimulation on both non-limited and K-limited cultures of $S$. elongatus.

\section{Exudation}

The ADA with A. variabilis showed clearing zones $(>6 \mathrm{~mm}$ ) for SPE-enriched medium equivalent to 6-7 g FM plants (240 ml medium) after 5 days incubation (set-up 1). An other ADA (setup 2) showed inhibitory effects of SPE-enriched medium equivalent to 4-5 g FM plants $(600 \mathrm{ml}$ medium) after one day incubation (Table 3), but some controls also showed slight clearing areas.
ADAs with exudates from Lake Naardermeer (set-up 3) also showed a strong inhibition of A. variabilis (Table 4), with the strongest inhibitory effect found at 20 April (when Stratiotes plants were still submerged). Controls, however, also showed inhibitory effects, but generally less strong than the exudates.

\section{Discussion}

In general, our results showed both stimulatory and inhibitory effects of Stratiotes extract and exudates on phytoplankton growth, with more 
Fig. 3 Growth relative to the control in non-limited (white bars) and P-limited cultures (grey bars) of Synechococcus elongatus (a) and Scenedesmus obliquus (b) over a range of Stratiotes extract concentrations. Bars indicate average values $(n=3)$, error bars are 1 SE. + and - indicate significant inhibitory and stimulatory effects on the growth of the phytoplankton species
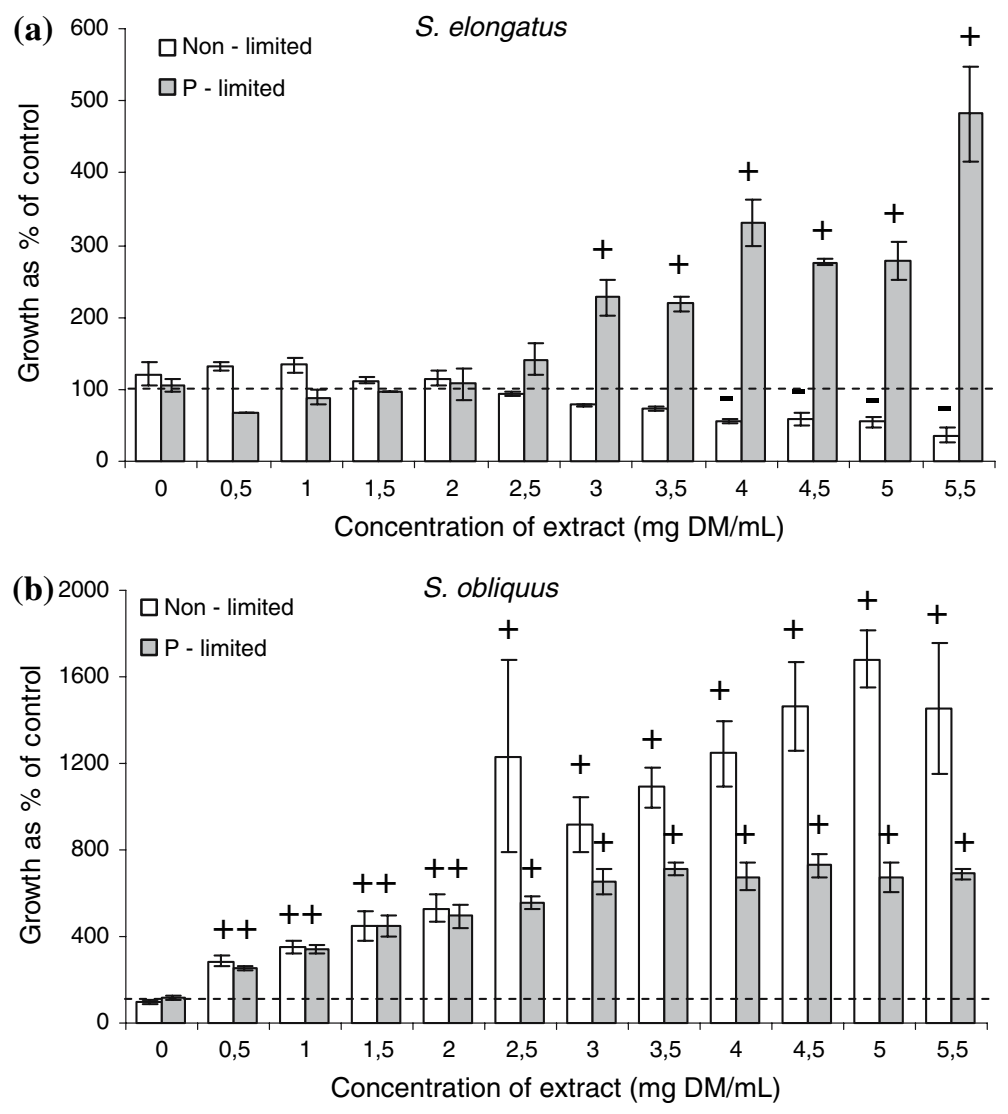

cyanobacteria than green algae being sensitive to allelopathic substances. Jasser (1994) and Körner \& Nicklisch (2002) showed similar results, but Mulderij et al. (2005b) observed no significant

Table 3 Results agar diffusion assays with Stratiotes exudates from microcosms (set-up 2)

\begin{tabular}{llll}
\hline $\begin{array}{lll}\text { Incubation } \\
\text { time [day] }\end{array}$ & $\begin{array}{l}\text { Methanol } \\
\text { fraction }(\%)\end{array}$ & \multicolumn{2}{l}{ Clearing area diameter $[\mathrm{cm}]$} \\
\cline { 3 - 4 } 1 & 50 & Exudate & Control \\
\hline & 90 & $0.8 /-$ & 0.6 \\
2 & 100 & $-/+$ & 0.7 \\
& 50 & $-/+$ & - \\
3 & 90 & $-/-$ & - \\
3 & 100 & $-/-$ & 1 \\
& 50 & $(+) /-$ & $(+)$ \\
& 90 & $1.1 /-$ & - \\
& 100 & $-/-$ & - \\
\hline
\end{tabular}

SPE-enriched aliquot equivalent to $600 \mathrm{ml}$ water $(=3.96 \mathrm{~g}$ FM) from the microcosms

( ), Inhibition less strong. Algal cells not completely absent in the clearing areas, only lower densities observed; -, no inhibition; +, slight inhibition differences in the sensitivity of cyanobacteria and green algae to allelopathic exudates from Stratiotes.

Similar to Fitzgerald (1969), P-limitation of S. elongatus did not increase the sensitivity of this cyanobacterium to Stratiotes extracts, while P-limited S. obliquus cultures showed opposite effects, corresponding with the hypothesis that nutrient-stressed organisms are more susceptible to allelopathy (Reigosa et al. 1999). K-limitation of $S$. elongatus did not intensify its sensitivity to Stratiotes extract. The stimulatory effects on K-limited target cells may have occurred because the extract acted as K-source. The extract might have been a P-source, because we observed both stimulatory and inhibitory effects of P-limited target cells upon extract addition. Organic phosphorus compounds might bind to $\mathrm{C} 18$ and may have been present in the $50 \%$ fraction, causing a stimulation of phytoplankton growth, while inhibitory compounds present in the $90-100 \%$ fractions resulted in adverse effects on 
Table 4 Results agar diffusion assay with $A$. variabilis and Stratiotes exudates from three sites in ditches near Lake Naardermeer (C18 fractions)

SPE-enriched aliquot equivalent to $600 \mathrm{ml}$ water from the ditch

a plants were still submerged

\begin{tabular}{|c|c|c|c|c|c|c|}
\hline \multirow[t]{2}{*}{ Site description } & \multirow{2}{*}{$\begin{array}{l}\text { Methanol } \\
\text { fraction (\%) }\end{array}$} & \multicolumn{5}{|c|}{ Clearing area diameter $(\mathrm{cm})$} \\
\hline & & 7 April $^{\mathrm{a}}$ & 20 April $^{\mathrm{a}}$ & 7 May & 21 May & 14 June \\
\hline \multirow{3}{*}{$\begin{array}{l}\text { Inside Stratiotes } \\
\text { (Ditch 1) }\end{array}$} & 50 & & $>3.0$ & - & 0.5 & (1) \\
\hline & 90 & & $>2.5$ & 1.0 & $(0.7)$ & 0.9 \\
\hline & 100 & & 0.8 & - & 1.5 & - \\
\hline \multirow{3}{*}{$\begin{array}{l}\text { Outside Stratiotes } \\
\quad(\text { Control, Ditch } 1)\end{array}$} & 50 & & 1.5 & - & 1.0 & $(0.5)$ \\
\hline & 90 & & 2.2 & $(+)$ & 0.8 & $(0.5)$ \\
\hline & 100 & & 1 & $(+)$ & - & 1 \\
\hline \multirow{3}{*}{$\begin{array}{l}\text { No Stratiotes (Control, } \\
\text { Ditch 2) }\end{array}$} & 50 & & 2.4 & $(+)$ & - & - \\
\hline & 90 & $>2.0$ & 2.1 & $(+)$ & 1.4 & 0.9 \\
\hline & 100 & & 0.8 & - & 0.5 & - \\
\hline
\end{tabular}

phytoplankton growth. Brammer (1979) and Brammer \& Wetzel (1984) stated that the absence of phytoplankton in the presence of Stratiotes is caused by nutrient limitation rather than allelopathy. Recent measurements in situ, however, did not reveal differences in nutrient content between Stratiotes stands and Stratiotesfree ditch water (Mulderij et al., unpublished data). Both extract and exudates exhibited allelopathic activity in our assays. Since we observed both stimulatory and inhibitory effects in P- or Klimited cultures, we argue against the hypothesis of Reigosa et al. (1999) that allelopathy acts more severely on already otherwise stressed target cells.

ADAs with Stratiotes exudates from laboratory cultures showed inhibitory effects after an incubation period of at least 3 days. Furthermore, exudates from a natural Stratiotes stand in Lake Naardermeer showed inhibitory effects, but some controls exhibited also a slight activity, which was, however, in general less strong than the exudates. Inhibitory effects were strongest when Stratiotes was still submerged, indicating that plants might start excreting allelopathic compounds at an early life-stage. This would be an effective strategy, because early in spring the competition with other photoautrophs is probably strongest. There are more indications for higher allelopathic activity in younger Stratiotes plants than in older ones (Mulderij et al., 2005a).

Compared to other studies (e.g., Gross et al., 1996; Gross et al., 2003) and based on the biomass of Stratiotes needed in both extract and exudate to achieve an inhibition, the allelopathic effects of Stratiotes shown in our study, are relatively weak. Mulderij et al. (2005a, b), on the contrary, observed inhibitory effects of Stratiotes exudates on phytoplankton growth ranging between 8 and $51 \%$. The allelopathic activity of plant extracts does not reflect the potential allelopathic activity of the same substances once they are excreted. The allelopathic activity of macrophytes further depends on the chemical nature of allelopathic substance(s) and on the rate at which they are produced and excreted. As a consequence, experiments with exudates are ecologically more relevant. Our first experiment with Stratiotes exudates showed significant inhibitory effects of SPE-enriched Stratiotes medium on the cyanobacterium $A$. variabilis, indicating that Stratiotes may excrete the allelopathic substances. However, exudation experiments overall did not yet show a clear effect and differed from previous experiments using macrophyte filtrates (Mulderij et al., 2005a, b). This might be due to an incomplete binding on the $\mathrm{C} 18$ filters used, or because the active compounds are otherwise lost during the SPE process. The inhibitory effects found in field exudates of macrophyte-free control stations might be caused by humic compounds, which are also known to have allelopathic properties (Serrano, 1992; Mulderij et al., unpublished data).

Knowing the chemical nature of allelopathically active compounds, facilitates studies of plant content, exudation and mode of action. Bioassays with PVPP treated extracts showed that the active substance(s) in Stratiotes are most likely not of phenolic nature. Smolders et al. (2000) showed that the phenolic content of Stratiotes leaves is relatively low compared to other macrophytes. Our results contradict those of Usenko et al. 
(2002) who proposed that the algicidal activity in Stratiotes is based on phenolic acids. Our further characterization of the allelopathic compounds in Stratiotes indicated that the allelopathic substance is heat-stable and moderately lipophilic.

\section{Conclusion}

Our assays showed both stimulatory and inhibitory effects of Stratiotes extract and exudates on phytoplankton, where cyanobacteria were more sensitive than other phytoplankton species. This differential sensitivity of phytoplankton species may affect the biomass and composition of phytoplankton populations under natural conditions. Nutrient limitation of phytoplankton cells did not increase their sensitivity to allelopathic extracts of Stratiotes. The substance(s) responsible for allelopathic inhibition of phytoplankton are moderately lipophilic and most likely not phenolic compounds.

Acknowledgements Parts of this study were supported by the Schure-Beijerink-Popping foundation (SBP 200129). We are grateful to Claudia Feldbaum for her assistance in the laboratory.

\section{References}

Alahari, A. \& S. K. Apte, 2004. A novel potassium deficiency-induced stimulon in Anabaena torulosa. Journal of Biosciences 29: 153-161.

Anthoni, U., C. Christophersen, J. Madsen, S. WiumAndersen \& N. Jacobsen, 1980. Biologically active sulphur compounds from the green alga Chara globularis. Phytochemistry 19: 1228-1229.

Bloemendaal, F. H. J. L. \& J. G. M. Roelofs, 1988. Waterplanten en Waterkwaliteit [in Dutch]. Stichting Uitgeverij KNNV, Utrecht, The Netherlands.

Brammer, E. S., 1979. Exclusion of phytoplankton in the proximity of dominant water soldier (Stratiotes aloides). Freshwater Biology 9: 233-249.

Brammer, E. S. \& R. G. Wetzel, 1984. Uptake and release of $\mathrm{K}^{+}, \mathrm{Na}^{+}$and $\mathrm{Ca}^{2+}$ by the water soldier, Stratiotes aloides L. Aquatic Botany 19: 119-130.

Burks, R. L., G. Mulderij, E. M. Gross, J. I. Jones, L. Jacobsen, E. Jeppesen \& E. Van Donk (in press). Center stage: The crucial role of macrophytes in regulating trophic interactions in shallow lake wetlands. In Bobbink, R., B. Beltman, J. T. A Verhoeven \& D. F. Whigham (eds), Wetlands: functioning, biodiversity, conservation and restoration. Ecological Studies.
Cook, C. D. K. \& K. Urmi-König, 1983. A revision of the genus Stratiotes (Hydrocharitaceae). Aquatic Botany 16: 213-249.

De Geus-Kruyt, M. \& S. Segal, 1973. Notes on the productivity of Stratiotes aloides in two lakes in the Netherlands. Polish Archive for Hydrobiology 20: 195-205.

Fitzgerald, G. P., 1969. Some factors in the competition or antagonism among bacteria, algae and aquatic weeds. Journal of Phycology 5: 351-359.

Flores, E. \& C. P. Wolk, 1986. Production by filamentous, nitrogen-fixing cyanobacteria of a bacteriocin and of other antibiotics that kill related strains. Archives of Microbiology 145: 215-219.

Fowler, J., L. Cohen \& P. Jarvis, 1998. Practical Statistics for Field Biology. John Wiley and Sons Ltd. Chichester, UK.

Fowler-Walker, M. J. \& S. D. Connell, 2002. Opposing states of subtidal habitat across temperate Australia: consistency and predictability in kelp canopy-benthic associations. Marine Ecology Progress Series 240: 4956.

Godmaire, H. \& D. Planas, 1986. Influence of Myriophyllum spicatum L. on the species composition, biomass and primary productivity of phytoplankton. Aquatic Botany 23: 299-308.

Gross, E. M., 2003. Allelopathy of aquatic autotrophs. Critical Reviews in Plant Sciences 22: 313-339.

Gross, E. M., D. Erhard \& E. Ivanyi, 2003. Allelopathic activity of Ceratophyllum demersum L. and Najas marina ssp. intermedia (Wolfgang) Casper. Hydrobiologia 506/509: 583-589.

Gross, E. M., H. Meyer \& G. Schilling, 1996. Release and ecological impact of algicidal hydrolysable polyphenols in Myriophyllum spicatum. Phytochemistry 41: 133-138.

Gross, E. \& R. Sütfeld, 1994. Polyphenols with algicidal activity in the submerged macrophyte Myriophyllum spicatum L. Acta Horticultura 381: 710-716.

Gross, E. M., C. P. Wolk \& F. Jüttner, 1991. Fischerellin, a new allelochemical from the freshwater cyanobacterium Fischerella muscicola. Journal of Phycology 27: 686-692.

Guillard, R. R. L. \& C. J. Lorenzen, 1972. Yellow-green algae with chlorophyllide $c$. Journal of Phycology 8: $10-14$.

Jasser, I., 1995. The influence of macrophytes on a phytoplankton community in experimental conditions. Hydrobiologia 306: 21-32.

Jasser, I, 1994. Influence of Ceratophyllum demersum on phytoplankton community in experimental conditions. Verhandlungen der Internationalen Vereinigung für Theoretische und Angewandte Limnologie 25: 2291-2295.

Jüttner, F., J. Leonhardt \& S. Mohren, 1983. Environmental factors affecting the formation of mesityloxide, dimethylallylic alcohol and other volatile compounds excreted by Anabaena cylindrica. Journal of General Microbiology 129: 407-412.

Kornatowski, J., 1938/84. Morphological forms of the water soldier. Acta Hydrobiologica 25/26: 145-156. 
Körner, S. \& A. Nicklisch, 2002. Allelopathic growth inhibition of selected phytoplankton species by submerged macrophytes. Journal of Phycology 38: 862871.

Loomis, W. D. \& Battaile J., 1966. Plant phenolic compounds and the isolation of plant enzymes. Phytochemistry 5: 423-438.

Lürling, M., 1999. The smell of water. Grazer-induced Colony Formation in Scenedesmus. PhD-thesis, University of Wageningen, The Netherlands.

Molisch, H., 1937. Der Einfluss einer Pflanze auf die andere - Allelopathie, Fisher, Jena.

Mulderij, G., W. M. Mooij \& E. van Donk, 2005a. Allelopathic growth inhibition and colony formation of the green alga Scenedesmus obliquus by the aquatic macrophytes Stratiotes aloides. Aquatic Ecology 39: 11-21.

Mulderij, G., W. M. Mooij, A. J. P. Smolders \& E. van Donk, 2005b. Inhibition of phytoplankton by allelopathic substances from Stratiotes aloides. Aquatic Botany 82: 284-296.

Mulderij, G., E. van Donk \& J. G. M. Roelofs, 2003. Differential sensitivity of green algae to allelopathic sub-stances from Chara. Hydrobiologia 491: 261-271.

Planas, D., F. Sarhan, L. Dube, H. Godmaire \& C. Cadieux, 1981. Ecological significance of phenolic compounds of Myriophyllum spicatum. Verhandlungen der Internationalen Vereinigung für Theoretische und Angewandte Limnologie 21: 1492-1496.

Reigosa, M. J., A. Sánchez-Moreiras, L. González, 1999. Ecophysiological approach in allelopathy. Critical Reviews in Plant Sciences 18: 577-608.

Scheffer, M, 1998. Ecology of shallow lakes. Chapman \& Hall, London. 357 pp.
Schrader, K. K., M. Q. DeRegt, C. S. Tucker \& S. O. Duke, 1997. A rapid bioassay for selective algicides. Weed Technology 11: 767-774.

Serrano, L., 1992. Leaching from vegetation of soluble polyphenolic compounds and their abundance in temporary ponds in the Donana National Park (SW Spain). Hydrobiologia 229: 43-50.

Smolders, A. J. P., L. H. T. Vergeer, G. van der Velde \& J. G. M. Roelofs, 2000. Phenolic contents of submerged, emergent, and floating leaves of aquatic and semi-aquatic macrophyte species: why do they differ? Oikos 91: 307-310.

Suikkanen, S., G. O. Fistarol \& E. Granéli, 2005. Effects of cyanobacterial allelochemicals on a natural plankton community. Marine Ecology Progress Series 287: 1-9.

Usenko, O. M., A. I. Sakevich \& V. D. Palamarchuk, 2002. Influence of phenol acids of hydrophytes on the development of plankton algae. International Journal on Algae 4: 20-28.

van Donk, E. \& W. J. van de Bund, 2002. Impact of submerged macrophytes including charophytes on phyto- and zooplankton communities: allelopathy vs other mechanisms. Aquatic Botany 72: 261-274.

Willis, R. J., 1985. The historical basis of the concept of allelopathy. Journal of the History of Biology 18: 71102.

Wium-Andersen, S., U. Anthoni, C. Christophersen \& G. Houen, 1982. Allelopathic effects on phytoplankton by substances isolated from aquatic macrophytes (Charales). Oikos 39: 187-190.

Wium-Andersen, S., 1987. Allelopathy among aquatic plants. Archiv für Hydrobiologie, Beiheft Ergebnisse der Limnologie 27: 167-172. 